\title{
Process design for gas condensate desulfurization and synthesis of nano-13X zeolite adsorbent: equilibrium and dynamic studies
}

\author{
Ghasem Bakhtiari $^{1} \cdot$ Hamid Ghassabzadeh ${ }^{2} \cdot$ Sayed Javid Royaee $^{2} \cdot$ Majid Abdouss $^{1} \cdot$ Mansour Bazmi $^{2}$
}

Received: 11 March 2018/Published online: 8 December 2018

(C) The Author(s) 2018

\begin{abstract}
This paper summarizes the results of a study of adsorption of sulfur compounds from a high-sulfur feed on improved spherical-shaped nano-AgX zeolite. For this purpose, the nano-AgX zeolite was initially synthesized and improved with silver compounds such as silver nitrate, and then it was utilized in the adsorption process. In order to investigate the equilibrium and dynamics of the adsorption process, adsorptive desulfurization of real feed (i.e., sour gas condensate from the South Pars gas field) was carried out in batch and continuous processes under several operating conditions; a temperature-dependent Langmuir isotherm model was used to fit the equilibrium data. The value of monolayer adsorption capacity $\left(q_{\mathrm{m}}\right)$ and adsorption enthalpy $(\Delta H)$ were calculated to be $1.044 \mathrm{mmol} / \mathrm{g}$ and $16.8 \mathrm{~kJ} / \mathrm{mol}$, respectively. Furthermore, a detailed theoretical model was employed in order to model the breakthrough experiments. The results revealed that an increase in the feed flow rate and $1 / T$ values will cause linear and exponential increase in the total mass transfer coefficient $\left(k_{\mathrm{s}}\right)$. Isotherm and dynamic breakthrough models were found to be in agreement with the experimental data.
\end{abstract}

Keywords Process design · Desulfurization · Dynamic adsorption $\cdot$ Gas condensate $\cdot$ Equilibrium

\section{Introduction}

The South Pars gas field in Iran, one of the world's largest gas fields, produces huge amounts of gas condensate. While gas condensate is frequently used as fuel in many countries, it can contain large amounts of sulfur compounds that are considered to be hazardous and harmful to the environment. Therefore, gas-producing countries need to reduce the sulfur content of their produced gas condensate to amounts less than $10 \mathrm{ppm}$, and for this purpose, a variety of desulfurization technologies have been introduced.

Edited by Xiu-Qin Zhu

Sayed Javid Royaee

royaeesj@ripi.ir

$凶$ Majid Abdouss

phdabdouss44@aut.ac.ir

1 Chemistry Department, Amirkabir University of Technology, P.O. Box 15875-4413, Tehran, Iran

2 Refining Technology Development Division, Research Institute of Petroleum Industry, Tehran, Iran
Nowadays, development of high-performance desulfurization techniques to produce sulfur-free motor fuels has become one of the important fields of study around the globe. Among different technologies to remove the sulfur compounds, the adsorption technology simply employs adsorbents such as zeolites, silica, carbonaceous material at low temperature and pressure to reduce the sulfur content; therefore, it has been an attractive solution for the customers due to the very user-friendly operational conditions.

For comparison sake, HDS (hydrodesulfurization), one of the conventional desulfurization processes employed at many refineries for sulfur removal from gas oil and gasoline, is a process with highly inconvenient requirements that lead to intensive operating conditions such as high $\mathrm{H}_{2}$ pressure (of about 60-100 bars) and high temperature of about $250-350{ }^{\circ} \mathrm{C}$ (Song 2003). Evidently, HDS technology has very high operating costs in comparison with adsorption technology.

While other technologies such as bio-desulfurization, extractive desulfurization and oxidative desulfurization have also been introduced, with the intention of producing very low sulfur fuels (Song 2003; Tang et al. 2015; Sano et al. 2004; Li et al. 2004), desulfurization by using an adsorption process is still more desirable in terms of 
operating conditions and expenditures. For example, biodesulfurization needs huge towers and oxidative desulfurization has significant losses in production of the low-sulfur product.

In this context, the selective adsorption desulfurization (SADS) technique is a method that is simply based on employing compounds which adsorb sulfur. Previous studies have revealed that impregnated and ion-exchanged zeolites, which are fairly inexpensive and have a high degree of selectivity, can be used as effective adsorbents for SADS (Sun et al. 2015; Tian et al. 2010).

In some studies, adsorbents for desulfurization have been developed using $\pi$-complex interactions and researchers have used transition metal ions, such as $\mathrm{Zn}^{2+}$, $\mathrm{Ag}^{+}, \mathrm{Cu}^{+}, \mathrm{Ni}^{2+}$ that were impregnated in zeolites, to selectively remove sulfur compounds from motor fuels (Song et al. 2014; Hernández-Maldonado et al. 2005). The desulfurization reaction mechanism indicates that the interaction between sulfur compounds and transition metal ions is stronger than that between transition metal ion and olefins or aromatics. While these $\pi$-complex interactions are capable of desulfurization, it is noticeable that the existence of a considerable amount of olefin and aromatic molecules in motor fuels will ultimately result in a decrease in desulfurization.

In the meantime, other researchers have focused on selectivity of ion-exchanged zeolites as adsorbents for sulfur removal from motor fuels (Lin et al. 2011; Bakhtiari et al. 2016a, b; Wang et al. 2009a, b; Duan et al. 2012; Shi et al. 2012). Investigation of the sulfur-metal interaction between the metal ions and the sulfur compounds in zeolite adsorbents has demonstrated high selectivity of exchanged zeolites for sulfur compounds (Lin et al. 2011; Bakhtiari et al. 2016a, b). Furthermore, a study of some exchanged zeolites with a high capacity for adsorption of sulfur compounds has revealed that the capacity of the adsorbents depends on their preparation conditions, and the metal ion content is an important factor influencing their effectiveness (Song et al. 2014).

In a nutshell, among several conventional and novel desulfurization technologies applied to achieve the necessary requirements for clean motor fuels, the adsorption process is considered as the most attractive solution, especially for desulfurization under ambient conditions (Rashtchi et al. 2006; Hasan et al. 2012; Shen 2012). Nowadays, numerous sorbents, e.g., impregnated or ionexchanged zeolites, have been synthesized and studied for desulfurization of motor fuels (Wang et al. 2009a, b; Yin et al. 2012; Wang and Yang 2007; Srivastav and Srivastava 2009; Cychosz et al. 2008; Bakhtiari et al. 2016a, b; Duan et al. 2012; Subhan et al. 2012).

Many sorbents have been evaluated for use in desulfurization processes. It is noteworthy that some interactions between the active sites of the sorbents and the sulfur compounds are viewed as an important disadvantage in desulfurization. Hence, many attempts have been made to determine the nature of these interactions. In this process, the interactions are mainly based on two major mechanisms (Duan et al. 2012; Shi et al. 2013), namely direct sulfur-metal interactions and $\pi$-complexation. In comparisons made of these two mechanisms, the effects of pore size of the sorbent on its sulfur removal efficiency have been neglected. Although some desulfurization studies have focused on meso- and nano-materials (Khaled 2015; Sentorun-Shalaby et al. 2011; Chen et al. 2009), the mainstream focus has been on sulfur removal through adsorption methods, which have been evaluated for thiophene, benzothiophene, dibenzothiophene and their derivatives. In some cases, experimental studies have demonstrated $\mathrm{CuY}$ zeolite as being a better sorbent for methyl benzothiophene and benzothiophene than $\mathrm{Ag} /$ MCM-41 used for the adsorption of alkylated benzothiophene. Given that $\mathrm{CuY}$ zeolite is known to have smaller pore sizes and lower sulfur capacity, the experiments indicate that in the case of adsorbents, there is no direct relationship between desulfurization performance and size of the pores. Zeolite structures are ideal materials for studying the relation between the desulfurization factor through adsorption and the pore size (Chen et al. 2009).

In the present study, $\mathrm{AgX}$ zeolite was prepared by liquid-phase impregnation of $\mathrm{Ag}^{+}$into the $\mathrm{X}$ zeolite, and then its adsorption efficiency for sulfur components of hydrocarbon feed solutions was investigated, with the intention of modeling the corresponding sulfur adsorption isotherm and breakthrough data.

\section{Experimental}

\subsection{Preparation of adsorbents}

For the separation of sulfur compounds from gas condensate, nanozeolite was used as a nanoadsorbent support (Fig. 1). In this separation process, various metal-zeolite adsorbents were used. Single crystals of sodium X zeolite were synthesized from hydrogel with a $3.4 \mathrm{Na}_{2} \mathrm{O}: \mathrm{Al}_{2}$ $\mathrm{O}_{3}: 2.9 \mathrm{SiO}_{2}: 150 \mathrm{H}_{2} \mathrm{O}$ molar ratio. The XRD pattern of the nano-X zeolite, dried at $100{ }^{\circ} \mathrm{C}$, is shown in Fig. 2 .

Nano-AgX zeolite was prepared by putting nano-X zeolite into a solution of $\mathrm{AgNO}_{3}$ (Merck, 99.99\%) with a total $\mathrm{Ag}^{+}$concentration of $4.5 \mathrm{wt} \%$ and impregnated at approximately $50{ }^{\circ} \mathrm{C}$ for $2 \mathrm{~h}$. The nano-AgX zeolite crystals were dried by increasing the temperature from 25 to $100{ }^{\circ} \mathrm{C}$ at a heating rate of $25^{\circ} \mathrm{C} / \mathrm{h}$ and calcined in a temperature range from 100 to $437^{\circ} \mathrm{C}$ using a heating rate of $2{ }^{\circ} \mathrm{C} / \mathrm{min}$. The system was maintained at this 


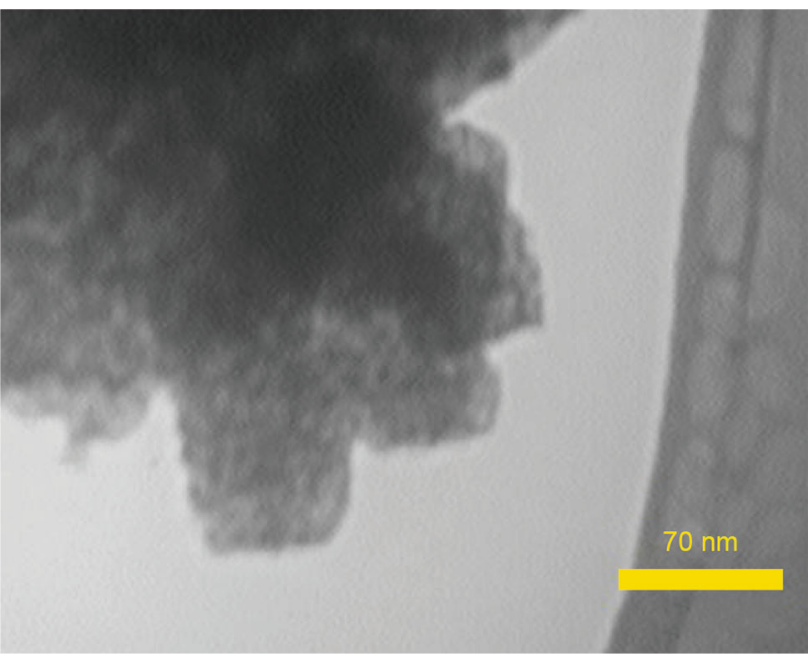

Fig. 1 TEM image of nanozeolite as an adsorbent support

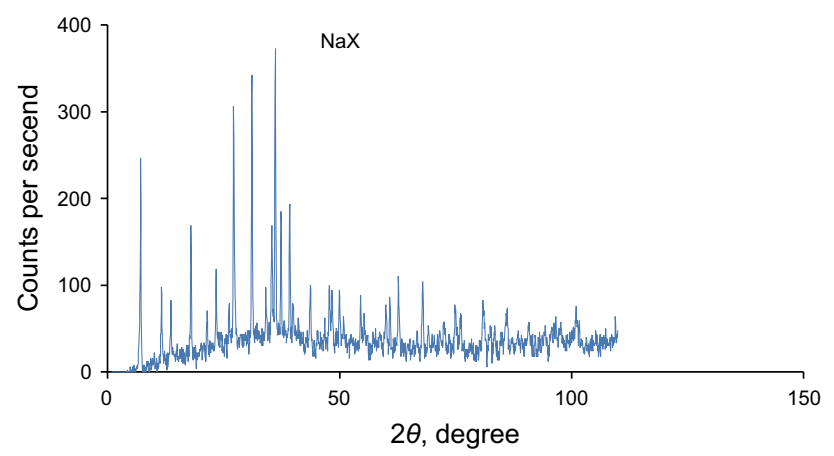

Fig. 2 XRD patterns of original NaX zeolite

temperature $\left(437{ }^{\circ} \mathrm{C}\right)$ for $4 \mathrm{~h}$. Finally, the nano- $\mathrm{AgX}$ zeolite crystals were cooled to room temperature and the crystals were observed to have a light color. Experimental details and physical characterization of $\mathrm{AgX}$ zeolite were described in the next sections.

\subsection{Characterization of adsorbents}

The Brunauer-Emmett-Teller (BET) surface areas of AgX zeolite were calculated from the $\mathrm{N}_{2}$ adsorption isotherms at $-196{ }^{\circ} \mathrm{C}$ using a Micromeritics ASAP 2020 surface area and porosity analyzer. The total pore volume was calculated from the $\mathrm{N}_{2}$ adsorbed amount at $P / P_{0}=0.98$ (Table 1).

The samples were completely pulverized, and X-ray diffraction (XRD) patterns were collected using a Bruker
D8 Advance diffractometer with a $\mathrm{Cu} K_{\alpha}$ monochromatic radiation source, operated at $40 \mathrm{kV}$ and $30 \mathrm{~mA}$, with a scan speed of $0.05 \% 0.2 \mathrm{~s}$. Chemical compositions of the adsorbents were determined by ICP-AES (Optima 2000DV, PerkinElmer).

The total sulfur content of the fuel was measured using an Analytik Jena multi EA 5000 total sulfur analyzer (TSA) by the pyrolysis method. The detection limit of the TSA was 500 ppbw. To determine the sulfur content as well as sulfur speciation, fuel samples were analyzed in an Agilent GC-7890 unit equipped with an EC-5 capillary column $30 \mathrm{~m}(\mathrm{~L}) \times 0.32 \mathrm{~mm}(\mathrm{ID})$ and a flame photometric detector.

\subsection{Preparation of feed}

Commercial gas condensate as a real feed was provided from the Iranian South Pars field. Commercial gas condensate with high sulfur concentration (more than 4500 ppmw) was caustic wash treated in $10 \% \mathrm{NaOH}$ solution for $10 \mathrm{~min}$ in a mixer at $1200 \mathrm{rpm}$. Total light mercaptanes were converted to mercaptides and transferred to the aqueous phase and then separated in a decanter. Total sulfur in the treated condensate measured by total sulfur device was 3800 ppmw.

Model feed for isotherm tests was provided from thiophene in isooctane (concentration $400 \mathrm{ppm}$ ).

\subsection{Batch experiments}

The adsorption isotherm of thiophene on improved adsorbent has been obtained by batch adsorption experiments. The solution consisting of isooctane and $400 \mathrm{ppm}$ thiophene was used as a model fuel. The model fuel and the impregnated adsorbent were mixed in a steel flask in a shaker-incubator machine for $4 \mathrm{~h}$ at $20,40,55$ and $75^{\circ} \mathrm{C}$. $\mathrm{AgX}$ zeolite was used as a representative zeolite sample. The model fuel (liquid) was separated from the adsorbents, and the sulfur concentration in the liquid model fuel was analyzed by a total sulfur analysis instrument.

The driving force behind all adsorptive liquid processes is the departure from adsorption equilibrium, so adsorption isotherms are important data in adsorption processes (Ghassabzadeh et al. 2010).

Several experiments in batch apparatus were carried out to analyze sulfur equilibrium concentration versus adsorbent uptake. The effect of adsorbent dosage on the
Table 1 Physical properties of nanozeolite adsorbent

\begin{tabular}{llllll}
\hline Sample & Metal impregnated, $\%$ & Metal ion & $L, \mathrm{~nm}$ & $V_{\mathrm{t}}, \mathrm{cm}^{3} / \mathrm{g}$ & $S_{\mathrm{BET}}, \mathrm{m}^{2} / \mathrm{g}$ \\
\hline Nano-AgX zeolite & 5.53 & $\mathrm{Ag}$ & 3.2 & 0.18 & 230.16 \\
\hline
\end{tabular}

$S_{\mathrm{BET}}:$ BET area, $\mathrm{m}^{2} / \mathrm{g} ; V_{\mathrm{t}}$ : total pore volume, $\mathrm{cm}^{3} / \mathrm{g} ; L$ : average pore size, $\mathrm{nm}$ 
adsorption of sulfur components is illustrated in Fig. 3. In these experiments, the initial condensate volume was $10 \mathrm{~mL}$. As expected, increasing the adsorbent content in the mixture increases the uptake of sulfur from the condensate. Increasing temperature increases the adsorption amount as shown in Fig. 3. The maximum uptake was 76, $65 \%, 47 \%$ and $45 \%$ at $75,55,40$ and $20^{\circ} \mathrm{C}$, respectively. Jiang and $\mathrm{Ng}$ (2010) and Sari et al. (2007) reported similar behavior for removal of sulfur components from gasoil onto NaY zeolite. Song et al. (2015) obtained an increase in sulfur adsorption capacity of $\mathrm{AgY}$ zeolite at higher temperatures. Also, Singh et al. (1988) have used red mud for the removal of 1-butanethiol from kerosene and diesel oils in a temperature range from 25 to $45^{\circ} \mathrm{C}$. They concluded that higher temperatures favor the removal efficiency.

\subsection{Breakthrough experiments}

In the adsorption test, a reciprocating pump with constant liquid flow was used to provide feed stream to the experimental setup for the adsorption test, as shown in Fig. 4. The flow rate in the setup was measured by a bypass line prior to injection to the reactor. Typically, $4.8 \mathrm{~g}$ of $\mathrm{AgX}$ zeolite was packed in a stainless steel reactor with an inner diameter of $10.51 \mathrm{~mm}$ and a length of $790 \mathrm{~mm}$. The total volume of the adsorption bed was $26,578 \mathrm{~mm}^{3}$. An appropriate particle size of adsorbent was obtained in the range between 140 and $260 \mu \mathrm{m}$. A tubular heat exchanger was used for heat treatment and temperature maintenance. Operational temperature for the adsorption process was 20 , 40,55 and $74{ }^{\circ} \mathrm{C}$. In this continuous adsorption test, sulfur adsorption capacity of the adsorbent reduced over time. The sulfur concentration of the feed and treated product after passing through the adsorbent was measured by a total sulfur analyzer (Analytik Jena multi EA 5000).

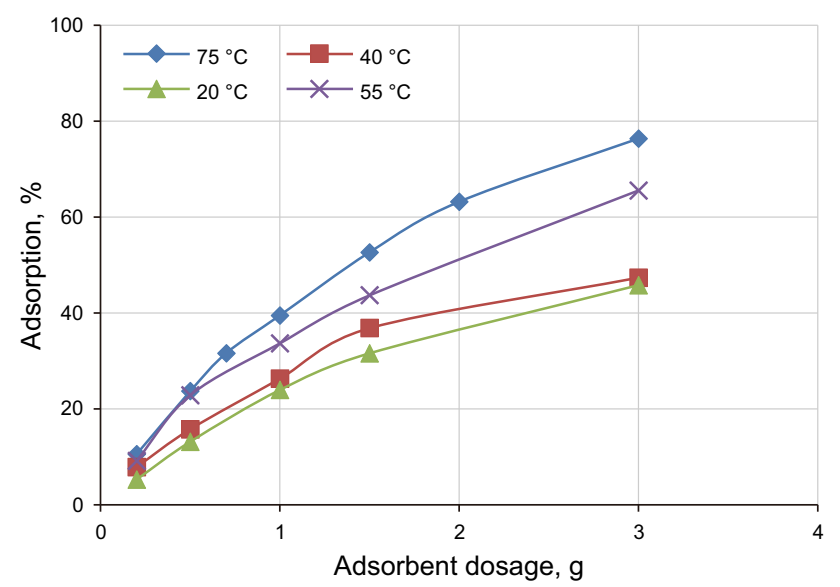

Fig. 3 Effect of adsorbent dosage on the adsorption of sulfur components from condensate

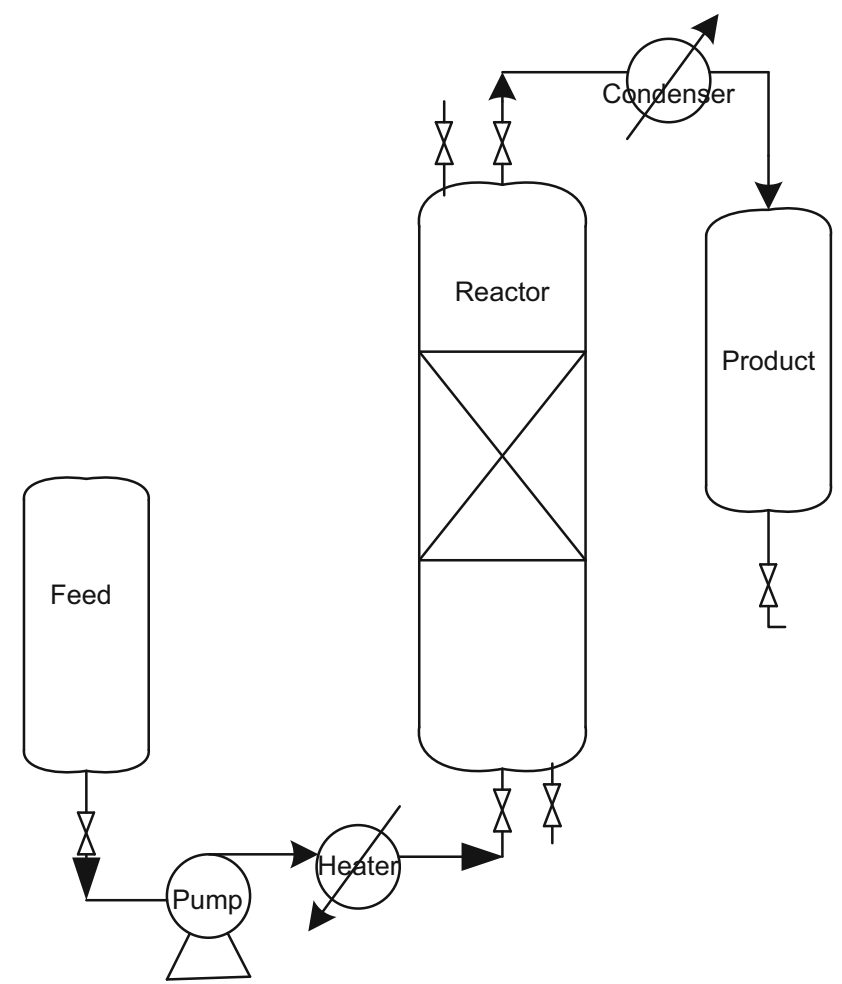

Fig. 4 Continuous breakthrough apparatus

Several breakthrough experiments were carried out in this apparatus. In these experiments, effects of feed flow rate and adsorption temperature were investigated. In Fig. 5, adsorption of sulfur (concentration vs. time) is illustrated. It shows that increasing the feed flow rate will cause faster breakthrough and a more narrow mass transfer zone (MTZ). Figure 6 illustrates sulfur adsorption breakthrough in four different temperatures. Adsorption isotherms revealed that increasing temperature will lead to

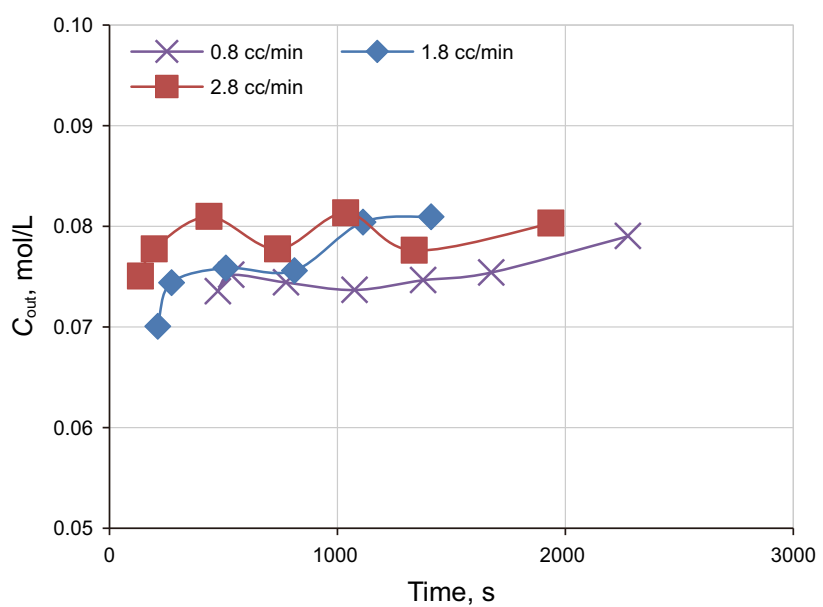

Fig. 5 Sulfur breakthrough versus time at different feed flow rates $(T$ : $40{ }^{\circ} \mathrm{C}$; feed sulfur concentration: $0.083 \mathrm{~mol} / \mathrm{L} ; C_{\text {out }}$ : product sulfur concentration) 


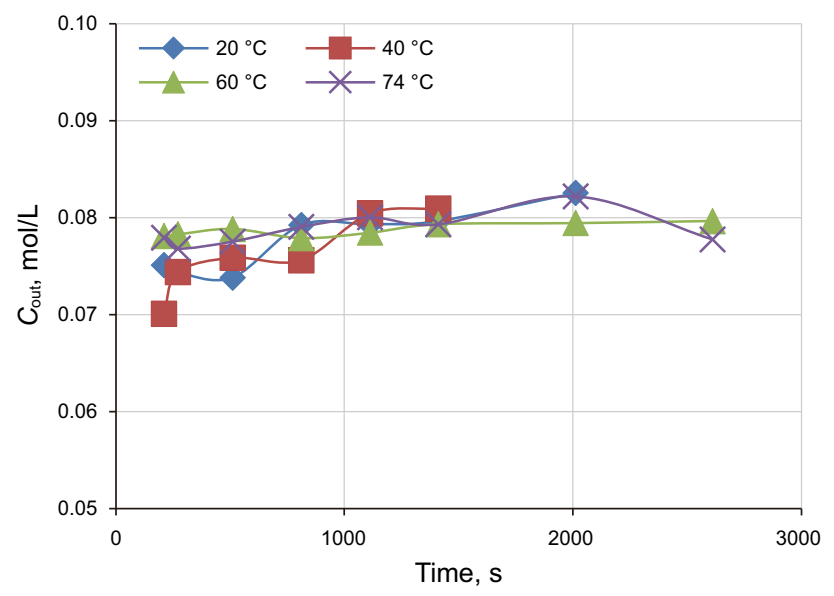

Fig. 6 Sulfur breakthrough versus time at different adsorption temperatures (feed flow rate: $1.8 \mathrm{cc} / \mathrm{min}$; feed sulfur concentration: $0.083 \mathrm{~mol} / \mathrm{L} ; C_{\text {out }}:$ product sulfur concentration)

more adsorption of sulfur components. Increasing temperature in breakthrough experiments (Fig. 6) caused MTZ and gave more time to saturate the zeolite.

\section{Results and discussion}

\subsection{Characterizations}

The Ag-impregnated adsorbents were dark, although the synthesized zeolites before impregnation were completely white. The XRD pattern for synthesized zeolite is shown in Fig. 2. Several peaks at $2.2^{\circ}, 2.80^{\circ}, 2.9^{\circ}, 3.3^{\circ}, 3.8^{\circ}, 7.6^{\circ}$, $9.0^{\circ}, 14.1^{\circ}, 38.1^{\circ}, 44.3^{\circ}, 64.5^{\circ}$ and $78.3^{\circ} \mathrm{A}$ are seen in the XRD pattern. There were no changes in NaX zeolite crystallinity (synthesized nanozeolite). XRD analysis was carried out to identify the NaX zeolite structure (Fig. 2). The NaX zeolite reflections did not demonstrate any significant differences in comparison with other $\mathrm{NaX}$ zeolites. XRD analysis revealed that synthesized $\mathrm{NaX}$ zeolite has similar X-ray diffraction intensity to that of $13 \mathrm{X}$ zeolite. There are similar peaks in the present XRD and original XRD patterns in the literature (Zhang et al. 2013). The peaks show that the $\mathrm{NaX}$ zeolite as an adsorbent support has kept its original crystal structure. Figure 2 shows the XRD pattern of this nanoadsorbent support. The position of peaks and their intensities were similar to the other reported data by Zhang et al. (2013). It was concluded that the nanoadsorbent support of $\mathrm{NaX}$ zeolite had been synthesized.

The FTIR spectrum for our nanozeolite is shown in Fig. 7. There are several peaks, at 667,751 and $974 \mathrm{~cm}^{-1}$ with a shoulder at $1054 \mathrm{~cm}^{-1}$ for skeletal vibration peaks and main characteristics as a tetrahedron stretching vibration peak. $\mathrm{T}-\mathrm{O}$ is a bending vibration peak at $458 \mathrm{~cm}^{-1}$,

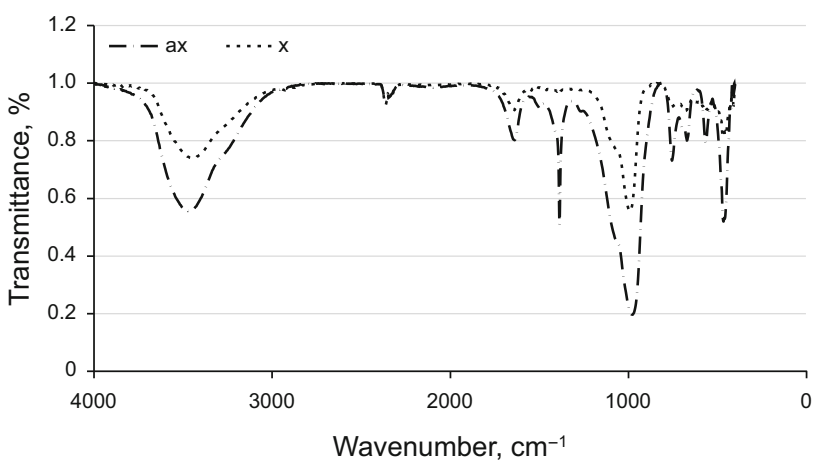

Fig. 7 FTIR patterns of original $\mathrm{NaX}$ zeolite (x) and $\mathrm{AgX}$ zeolite (ax)

and double 6-ring vibration peak of $563 \mathrm{~cm}^{-1}$ and peak of $3466 \mathrm{~cm}^{-1}$ show the $\mathrm{Si}-\mathrm{OH}$ on the zeolite structure, and the main characteristic of peak at $617 \mathrm{~cm}^{-1}$ is for $\mathrm{AgX}$ zeolite. The IR analyses reveal that the synthesized nanozeolite after silver impregnation shows little change in the nanozeolite structure. The absorption bands from 1350 to $1450 \mathrm{~cm}^{-1}$ indicate the amorphous zeolite structure of the samples. These are due to the progress of the amorphous phase to crystalline zeolite phase. Amorphous phase bands are completely weak in NaX zeolite. Only absorption bands for pure zeolite remained. The FTIR spectra for the nano-AgX zeolite are shown in Fig. 7 with (ax), and the FTIR spectra for the nano-NaX zeolite are shown with (x) in Fig. 7.

The role of pores in the adsorbent structure and their performance due to surface chemistry and surface complex formation are very important. The $\mathrm{N}_{2}$ isotherm for the adsorbent structure for adsorption/desorption at $-196{ }^{\circ} \mathrm{C}$ is shown in Fig. 8. This figure shows distribution of pores for $\mathrm{AgX}$ zeolite and $\mathrm{NaX}$ zeolite and their isotherms. The Barrett-Joyner-Halenda (BJH) method showed pores with uniform distribution. The Brunauer-Emmett-Teller (BET) method for porous material (for example, zeolite

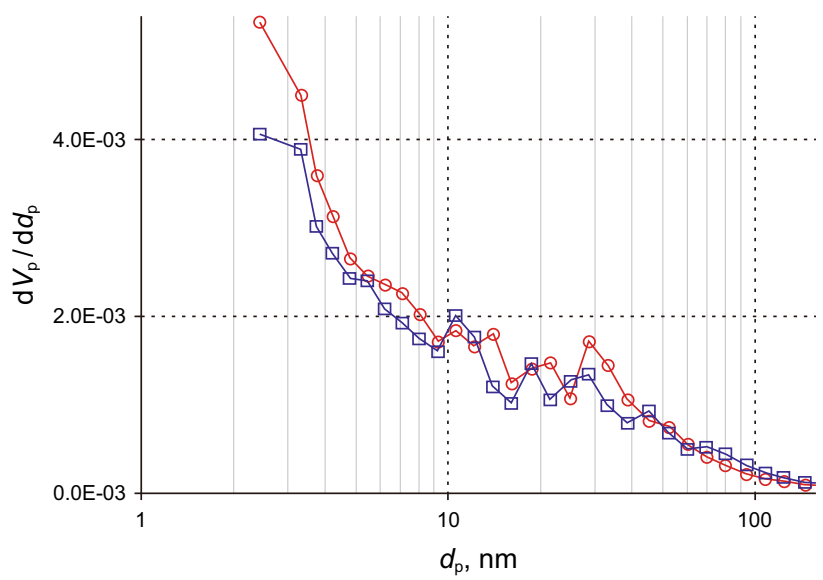

Fig. 8 BET patterns of original $\mathrm{NaX}$ zeolite (circle) and $\mathrm{AgX}$ zeolite (square). ( $d_{\mathrm{p}}$ : pore size; $V_{\mathrm{p}}$ : pore volume) 
adsorbents) provided the surface area in a pressure range of 0.01-0.25 (Fig. 8). Table 1 demonstrates total pore volume and BET area and pore size in the nanoadsorbent by filling the nanoadsorbent with liquid nitrogen in boiling operation conditions. These data (Table 1) explain the fact that the synthesized $\mathrm{X}$ zeolite particles have low crystallinity meaning that the $\mathrm{X}$ zeolite particles have relatively high total pore volume.

Figure 1 shows a TEM image of the new nanozeolite and precipitated clusters in nanosize that were synthesized from hydrogel. Average size for nanocrystals is about 30 nm (Fig. 1).

\subsection{Adsorption isotherm evaluation}

In the following, the obtained experimental data are used for estimating adsorption isotherm model parameters. The adsorption isotherms reveal the specific relation between the concentration of sorbent and its sorption degree onto the adsorbent surface at specific temperature.

The Langmuir adsorption isotherm model assumes that adsorption takes place at specific homogeneous sites within the adsorbent. This model can be applied successfully in many monolayer adsorption processes. This isotherm model can be expressed as:

$q_{\mathrm{e}}=\frac{q_{\mathrm{m}} \cdot K_{\mathrm{L}} \cdot C_{\mathrm{e}}}{1+K_{\mathrm{L}} \cdot C_{\mathrm{e}}}$

where $q_{\mathrm{e}}$ and $C_{\mathrm{e}}$ are the uptake of adsorbent and adsorbate concentration in equilibrium; $q_{\mathrm{m}}$ is the monolayer adsorption capacity ( $\mathrm{mmol} / \mathrm{g})$, and it is a temperature-independent constant; and $K_{\mathrm{L}}$ is the Langmuir adsorption equilibrium constant $(\mathrm{mmol} / \mathrm{cc})$ at a specific temperature. The temperature dependence of adsorption equilibrium constant $K_{\mathrm{L}}$ follows the van't Hoff equation:

$K_{\mathrm{L}}=K_{\mathrm{L} .0} \cdot \exp \left(-\frac{\Delta H_{0}}{R T}\right)$

A least squares method was used to estimate Langmuir model parameters using experimental data at different temperatures. $q_{\mathrm{m}}, K_{\mathrm{L} .0}$ and $\Delta H$ were selected as tuning parameters. Minimization of the least squares objective function was done by the Nelder-Mead algorithm. NelderMead is a direct search method based on the simplex algorithm (Ruthven 1984). Observed results are summarized in Table 2. The final value of the objective function after minimization was $1.2 \times 10^{-8}$ which is relatively small.

In the next step, for verifying isotherm model results, the average absolute value of relative error (AARE) values were calculated at different temperatures. AARE is used to evaluate relative error of model predictions compared to
Table 2 Isotherm model parameter values for the adsorption of sulfur components onto $\mathrm{AgX}$

\begin{tabular}{lllll}
\hline Isotherm & $T,{ }^{\circ} \mathrm{C}$ & $q_{\mathrm{m}}, \mathrm{mmol} / \mathrm{g}$ & $K_{\mathrm{L} .0}, \mathrm{~L} / \mathrm{g}$ & $-\Delta H, \mathrm{~kJ} / \mathrm{mol}$ \\
\hline Langmuir & $20,40,55,74$ & 1.044 & 3393.9 & -16.84 \\
\hline
\end{tabular}

$q_{\mathrm{m}}$ : saturation capacity of adsorbent, $\mathrm{mmol} / \mathrm{g}$

experimental observed values. AARE is calculated from following equation:

$\begin{aligned} \text { AARE } \%= & \frac{1}{N} \sum_{i=1}^{N} \frac{\mid \text { Predicted value }- \text { Experimental value } \mid}{\text { Experimental value }} \\ & \times 100\end{aligned}$

In which $N$ is the number evaluated points. The AARE values were $5.2 \%, 13.8 \%, 6.9 \%$ and $5.5 \%$ at $20,40,55$ and $75{ }^{\circ} \mathrm{C}$, respectively. Results of Langmuir isotherm models along with experimentally observed data are also represented in Fig. 9. Results reveal good agreement between Langmuir isotherm prediction and experimental data.

The value of $q_{\mathrm{m}}$ is calculated to be $1.044 \mathrm{mmol} / \mathrm{g}$. This parameter represents maximum theoretical uptake capacity of adsorbent. A comprehensive coverage of different adsorbents under different environmental conditions can be found in the format of several publications. It may be seen that $q_{\mathrm{m}}$ values differ widely for different adsorbents. From Table 3, it can be concluded that $\mathrm{AgX}$ zeolite exhibits good adsorption capacity toward sulfur components.

\subsection{Breakthrough evaluation}

In this section, physical phenomena governing breakthrough experiments are modeled and related mathematical

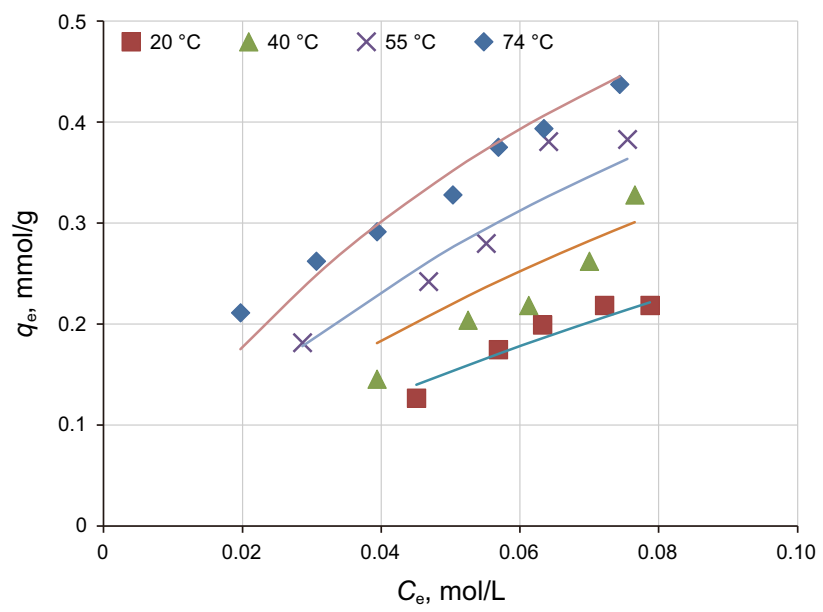

Fig. 9 Isotherm data plot (points: experimental results; lines: Langmuir isotherm; $C_{\mathrm{e}}$ : sulfur concentration; $q_{\mathrm{e}}$ : adsorption capacity) 
Table 3 Comparison of adsorption potential of various adsorbents for sulfur component removal

\begin{tabular}{lllll}
\hline$\#$ & Adsorbent & Sulfur component & $q_{\mathrm{m}}, \mathrm{mmol} / \mathrm{g}$ & References \\
\hline 1 & AgY zeolite & DBT & $1.10-1.23$ & Jiang and Ng (2010) \\
2 & CeY zeolite & Thiophene & 0.43 & Lin et al. (2011) \\
3 & Nanofiber & DBTO $_{2}$ & 0.26 & Ogunlaja et al. (2014) \\
4 & MWCTN & DBT & 0.73 & Khaled (2015) \\
5 & Activated carbon $/ \mathrm{Al}_{2} \mathrm{O}_{3}$ & DBT & 2.6 & Nazal et al. (2015) \\
\hline
\end{tabular}

$q_{\mathrm{m}}$ : saturation capacity of adsorbent, $\mathrm{mmol} / \mathrm{g}$ equations are described. The following assumptions are considered in breakthrough mathematical modeling:

- All sulfur components are lumped into a single sulfur pseudo-component.

- Only sulfur pseudo-component is adsorbed on $\mathrm{AgX}$ zeolite.

- There is no pressure drop across the bed, because bed dimensions are relatively small.

- The liquid velocity is constant along the bed.

- Liquid density is constant.

- Breakthrough experiments are done in isothermal conditions.

- Radial distribution of solutes was neglected in the fixed bed.

- All mass transfer resistances including intra-pellet mass transfers and the adsorption/desorption reactions are lumped into a single, overall mass transfer coefficient.

For the liquid phase, the mass balance equation will be as follows:

$v_{\mathrm{L}} \frac{\partial C_{\mathrm{bk}}}{\partial z}+\epsilon \frac{\partial C_{\mathrm{bk}}}{\partial t}+(1-\epsilon) \rho_{\mathrm{s}} \frac{\partial q}{\partial t}-\epsilon D_{\mathrm{ax}} \frac{\partial^{2} C_{\mathrm{bk}}}{\partial z^{2}}=0$

where $C_{\mathrm{bk}}$ is the molar concentration of adsorbate $(\mathrm{kmol} /$ $\left.\mathrm{m}^{3}\right) ; v_{\mathrm{L}}$ is the liquid superficial velocity $(\mathrm{m} / \mathrm{s}) ; \varepsilon$ is the bed interparticle void fraction; $\rho_{\mathrm{s}}$ is the solid bulk density $(\mathrm{kg} /$ $\left.\mathrm{m}^{3}\right) ; q$ is the adsorbate loading on adsorbent $(\mathrm{kmol} / \mathrm{kg})$ at any time $(t)$ and distance $(z) . D_{\mathrm{ax}}$ is the axial dispersion coefficient estimated from the following correlation (Press et al. 1992):

$\frac{\nu_{\mathrm{L}} r_{\mathrm{p}}}{D_{\mathrm{ax}}}=0.2+0.011\left(\frac{R e}{\epsilon}\right)^{0.48}$

where $r_{\mathrm{p}}$ is the adsorbent particle radius (m) and $R e$ is the particle Reynolds number $\left(\frac{r_{\mathrm{p}} \rho_{\mathrm{L}} \nu_{\mathrm{L}}}{\mu}\right)$. For the solid adsorbent phase, the mass balance equation can be expressed as follows:

$\frac{\partial q}{\partial t}=k_{\mathrm{s}}\left(q_{\mathrm{e}}-q\right)$

$q_{\mathrm{e}}$ is the adsorbate loading on the adsorbent that would be at equilibrium with the actual liquid-phase concentration.
The value of $q_{\mathrm{e}}$ is calculated from the isotherm model Eq. (1). $k_{\mathrm{s}}$ is the overall mass transfer coefficient (1/s).

Equation (4) is a second-order partial differential equation (PDE) which is coupled with an ordinary differential equation (ODE) (6) and an algebraic Eq. (1). Solving these equations requires initial and boundary conditions. These conditions are specified as follows:

$\left.C_{\mathrm{bk}}(z \cdot t)\right|_{t=0}=0$

$\left.q(z \cdot t)\right|_{t=0}=0$

$\left.C_{\mathrm{bk}}(z \cdot t)\right|_{z=0}=C_{\mathrm{bk}}^{0}$

$\left.\frac{\partial C_{\mathrm{bk}}(z \cdot t)}{\partial z}\right|_{z=L}=0$

A central finite difference discretization method was used to convert these PDE and ODE equations to a system of algebraic equations. All these equations were solved numerically. All properties in Eqs. (4)-(10) are known apart from $k_{\mathrm{S}}$ which should be estimated based on experimental data. $K_{\mathrm{L}}$ and $q_{\mathrm{m}}$ in Eq. (1) as described in the previous section are estimated from batch experiment results. All other physical and chemical properties which are required in the model are summarized in Table 4.

For tuning the overall mass transfer coefficient $\left(k_{\mathrm{s}}\right)$, an objective function, Eq. (11) was defined subject to Eqs. (1) and (4-6) representing the difference between the simulation results and operating data from the adsorber tube outlet. The Nelder-Mead optimization algorithm (Ruthven 1984) was employed to minimize the objective function.

$\min _{k_{\mathrm{s}}} \sum_{i=1}^{i=n}\left[\frac{C_{\mathrm{bk}}\left(z=L \cdot t_{i}\right)-C_{\exp }\left(t_{i}\right)}{C_{\exp }\left(t_{i}\right)}\right]^{2}$

In this equation $C_{\mathrm{exp}}\left(t_{i}\right)$ and $C_{\mathrm{bk}}\left(z=L \cdot t_{i}\right)$ represent the measured value and model output at the bed outlet in time $t_{i}$, respectively. In Table 4 , the final values of the objective function (11) and tuned mass transfer coefficient $\left(k_{\mathrm{s}}\right)$ are reported. In all breakthrough experiments, the observed objective function values are relatively small and of the order of $2 \times 10^{-4}$ indicating good agreement between experimental measured values and model outputs. In Fig. 10a-g, experimental and model sulfur outlet 
Table 4 Optimized equation results by tuning the mass transfer coefficient $\left(k_{\mathrm{s}}\right)$

\begin{tabular}{lllll}
\hline$\#$ & $\begin{array}{l}\text { Feed flow rate, } \\
\text { cc/min }\end{array}$ & Temperature, ${ }^{\circ} \mathrm{C}$ & $k_{\mathrm{s}}, 1 / \mathrm{s}$ & Objective function values \\
\hline 1 & 1.8 & 20 & $7.90 \mathrm{E}-05$ & $2.27 \mathrm{E}-04$ \\
2 & 1.8 & 40 & $5.43 \mathrm{E}-05$ & $8.82 \mathrm{E}-05$ \\
3 & 1.8 & 60 & $3.02 \mathrm{E}-05$ & $3.00 \mathrm{E}-04$ \\
4 & 1.8 & 74 & $2.56 \mathrm{E}-05$ & $2.86 \mathrm{E}-04$ \\
5 & 0.8 & 40 & $5.16 \mathrm{E}-05$ & $2.59 \mathrm{E}-04$ \\
6 & 2.8 & 40 & $6.38 \mathrm{E}-05$ & $2.11 \mathrm{E}-04$ \\
\hline
\end{tabular}

(a)

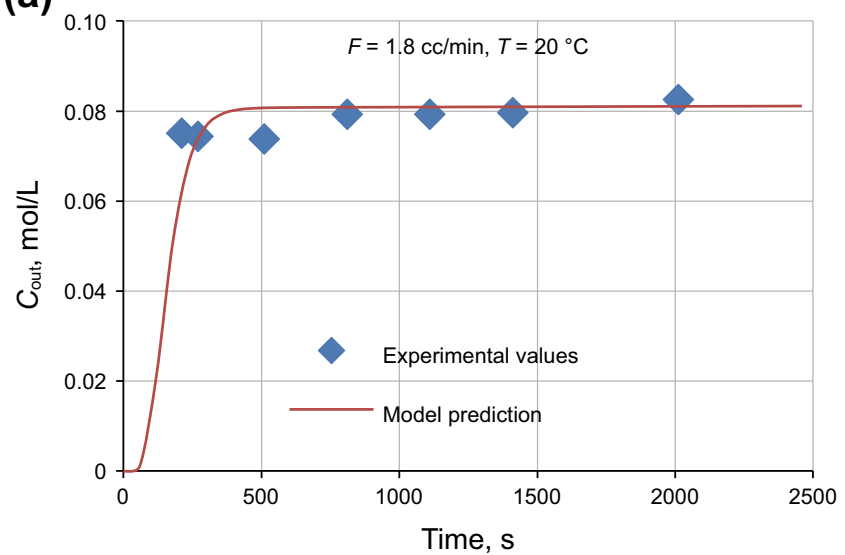

(c)

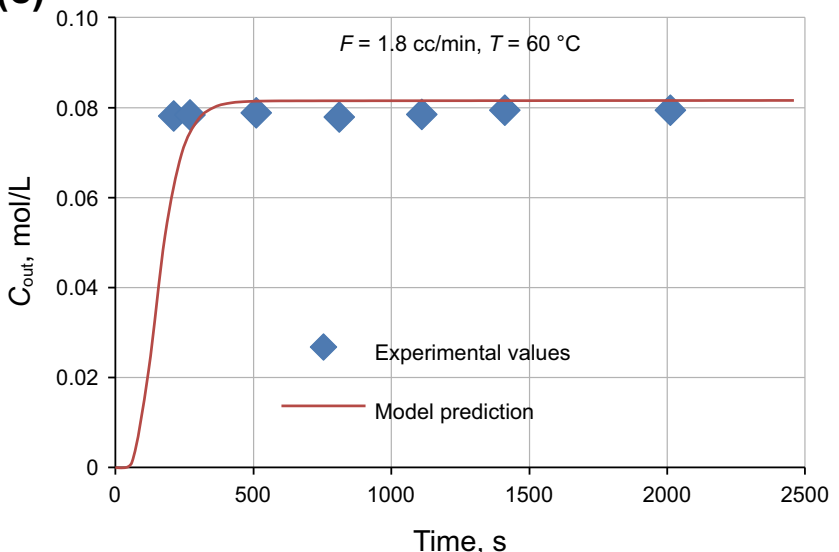

(e)

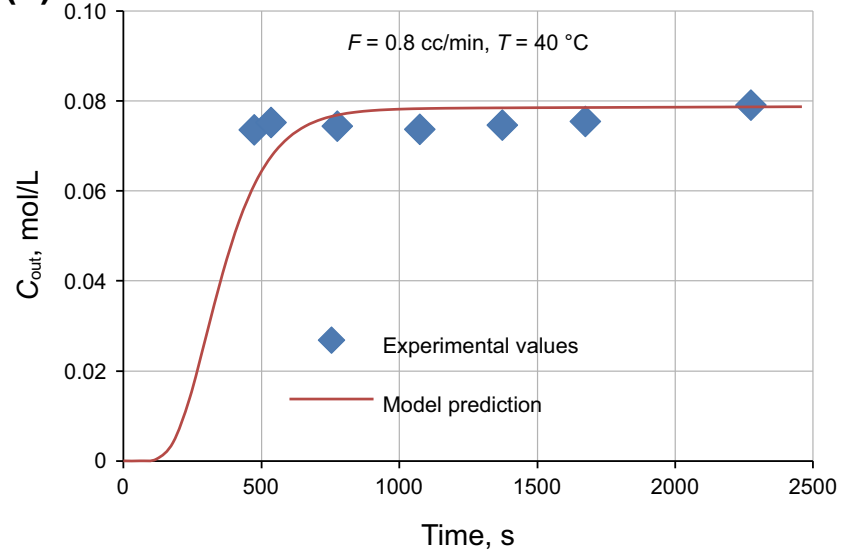

(b)

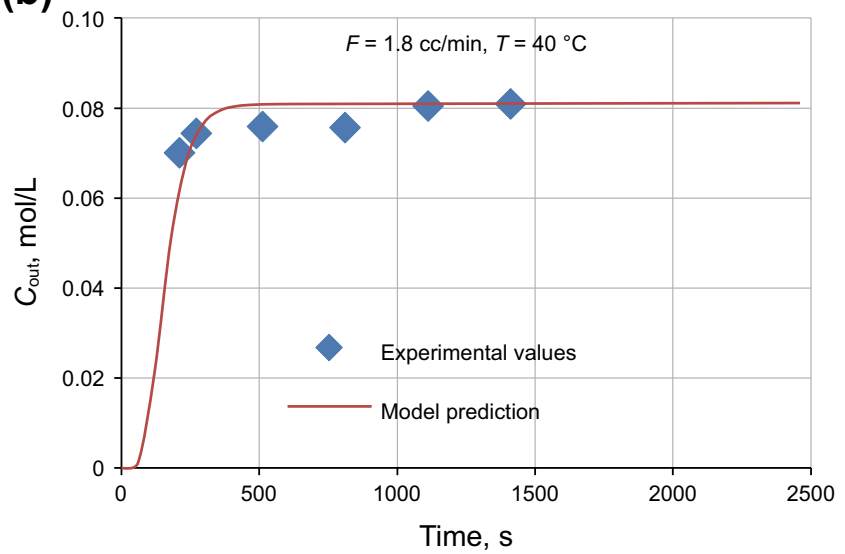

(d)

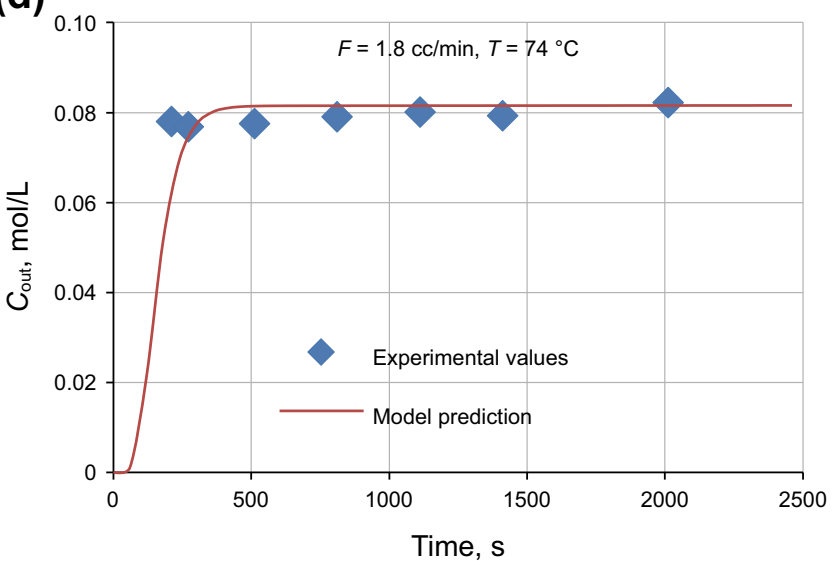

(f)

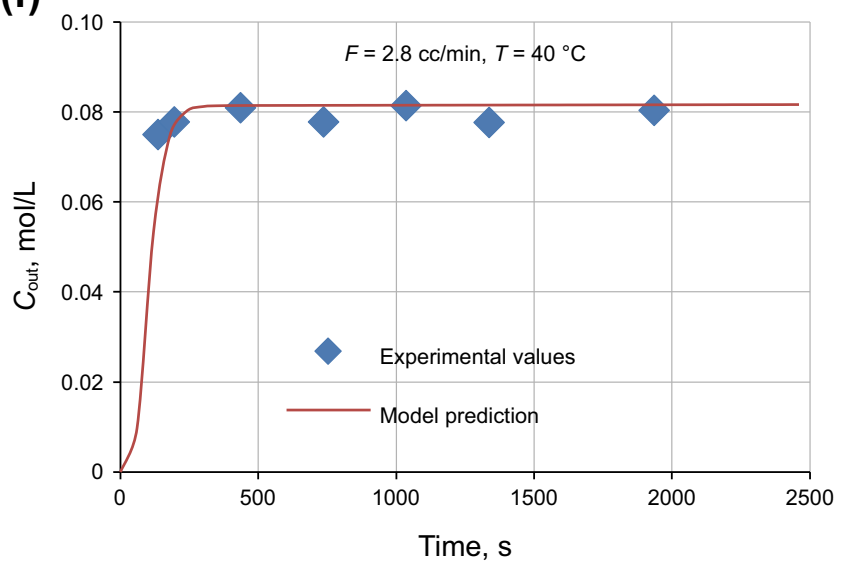

Fig. 10 Experimental and model breakthrough curves ( $C_{\text {out }}$ : product sulfur concentration, $F$ : feed flow rate) 
concentrations are also compared versus run time. Results show good agreement of model results with experimental data.

The results in Table 4 show that by increasing the adsorption temperature at a constant feed flow rate $(1.8 \mathrm{cc} /$ $\mathrm{min})$, the total mass transfer coefficient was decreased. The values of $\ln k_{\mathrm{s}}$ versus $1 / T$ are plotted in Fig. 11. It illustrates that there is a linear relationship between $\ln k_{\mathrm{s}}$ and $1 / T$. Hence, an empirical correlation between the total mass transfer coefficient and adsorption temperature can be expressed as the following equation:

$k_{\mathrm{s}}=k_{\mathrm{s} 0} \mathrm{e}^{-\frac{E}{R T}}$

From Fig. 11, the values of $k_{\mathrm{s} 0}$ and $E$ in Eq. (12) are calculated to be $4.050 \times 10^{-8}(1 / \mathrm{s})$ and $-18.53(\mathrm{~kJ} / \mathrm{mol})$, respectively. A negative value of $E$ in this equation means that an increasing temperature will lead to a smaller mass transfer coefficient $\left(k_{\mathrm{s}}\right)$. A lower mass transfer coefficient

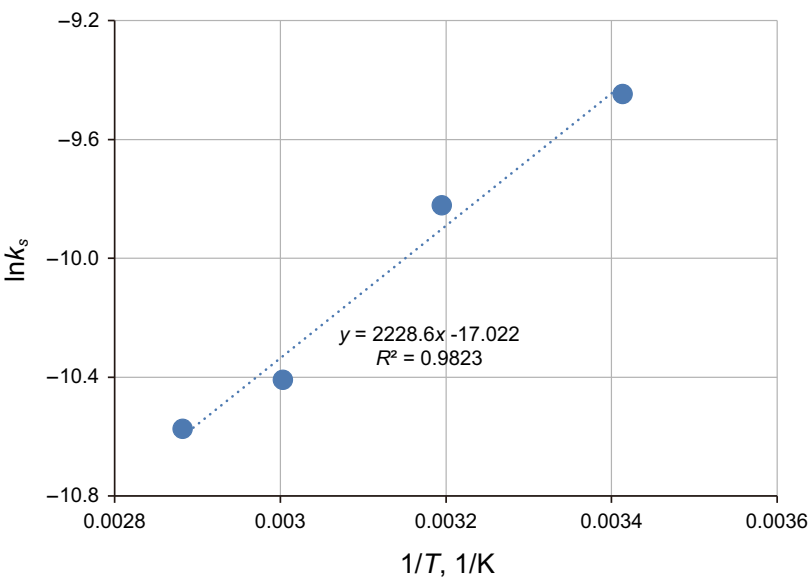

Fig. 11 Variation of total mass transfer coefficient with temperature (feed flow rate: $1.8 \mathrm{cc} / \mathrm{min}$ )

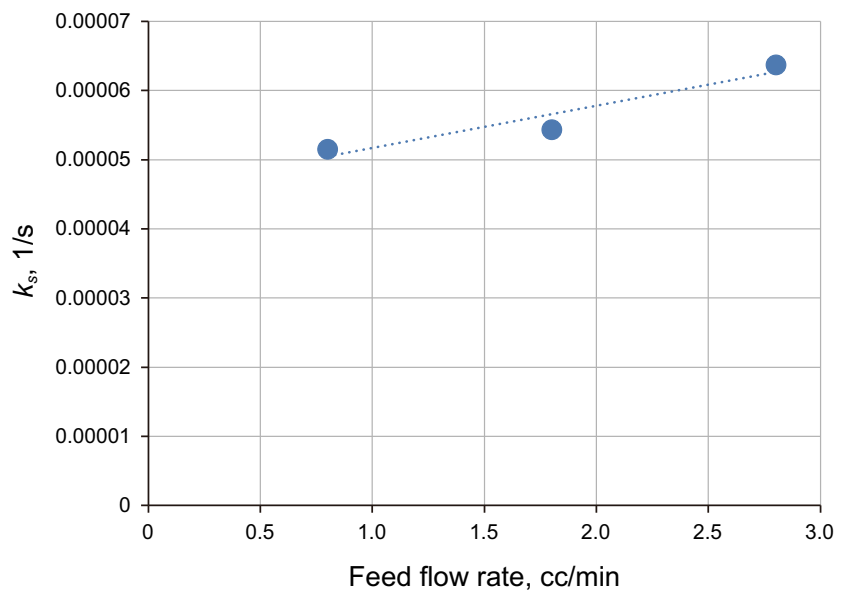

Fig. 12 Variation of total mass transfer coefficient $\left(k_{\mathrm{s}}\right)$ with feed flow rate (temperature: $40^{\circ} \mathrm{C}$ ) means a lower mass transfer rate. Also, as presented in isotherm evaluations, increasing temperature will cause a higher adsorption capacity. Higher adsorption capacity and lower mass transfer rate will lead to a wider mass transfer zone (MTZ) in breakthrough curves which is in agreement with experimental results in Fig. 6.

Figure 12 illustrates that increasing the feed flow rate at constant temperature has slightly increased the total mass transfer coefficient. A higher mass transfer rate will lead to a more restricted MTZ which is in agreement with observations in Fig. 5: A higher flow rate causes a fast breakthrough and a narrow MTZ.

\section{Conclusion}

In this research, adsorption of sulfur components on $\mathrm{AgX}$ zeolite has been studied. Experiments were carried out in a batch container that showed increasing adsorption temperature will lead to more uptake of sulfur components. The maximum sulfur uptake was about $76 \%$ at $74{ }^{\circ} \mathrm{C}$. A Langmuir adsorption model was used to model adsorption isotherm data. Good agreement between the model and experimental data was obtained. The presented Langmuir model is capable of predicting isotherms of sulfur adsorption on $\mathrm{AgX}$ zeolite in the range of $20-74{ }^{\circ} \mathrm{C}$. Our experimental results and calculated adsorption enthalpy $(\Delta H>0)$ revealed that the adsorption of sulfur components on $\mathrm{AgX}$ zeolite is an endothermic process.

In addition to adsorption equilibrium studies, breakthrough evaluations were carried out in a dynamic adsorption apparatus. Adsorption temperature and feed flow rates were investigated in these studies. Conservative mass transfer equations were applied to model concentration of the sulfur components in the column outlet. In the represented model, all mass transfer resistances were lumped into an overall mass transfer coefficient $\left(k_{\mathrm{s}}\right)$. An objective function was defined to tune the overall mass transfer coefficient based on experimental results. Good agreement between the model output and experimental data was obtained. Results of the model showed that the breakthrough time of the sulfur removal would occur in the range of 36-138 s from the beginning of the adsorption process. Increasing the feed flow rate will lead to a faster breakthrough. Total mass transfer coefficient values were calculated at different adsorption temperatures. The results emphasized that the overall mass transfer coefficient was correlated with an empirical exponential equation $\left(k_{\mathrm{s}}=k_{\mathrm{s} 0} \mathrm{e}^{-\frac{E}{R T}}\right)$. Also, the increasing feed flow rate caused a slight increase in the mass transfer coefficient as expected. Experimental results and the model results revealed that 
low feed flow rates and high adsorption temperature will cause a wide MTZ in breakthrough curves.

Finally, it was concluded that nano-AgX zeolite was successfully synthesized. The experimental results demonstrated that nano-AgX zeolite could effectively adsorb sulfur compounds from the gas condensate feed. Isotherm investigations revealed high performance for the sorption of sulfur compounds on the nanoadsorbent. Mathematical models were studied for investigation of different factors affecting the dynamic behavior of adsorption to adsorbents. The mass transfer coefficient and the factors influencing it were investigated and reported.

Acknowledgements The authors wish to thank the Chemistry Department, Amirkabir University of Technology, Tehran, Iran, and the Refining Technology Development Division, Research Institute of Petroleum Industry, Tehran, Iran, for their assistance.

Open Access This article is distributed under the terms of the Creative Commons Attribution 4.0 International License (http://creative commons.org/licenses/by/4.0/), which permits unrestricted use, distribution, and reproduction in any medium, provided you give appropriate credit to the original author(s) and the source, provide a link to the Creative Commons license, and indicate if changes were made.

\section{References}

Bakhtiari G, Abdouss M, Bazmi M, Royaee SJ. Optimization of sulfur adsorption over Ag-zeolite nanoadsorbent by experimental design method. Int J Environ Sci Technol. 2016a;13:803-12. https://doi.org/10.1007/s13762-015-0910-2.

Bakhtiari Gh, Abdouss M, Bazmi M, Royaee SJ. High efficiency desulfurization of gas condensate by adsorption method on improved zeolite. AFINIDAD. 2016b;574:148-55.

Chen H, Wang Y, Yang FH, Yang RT. Desulfurization of high-sulfur jet fuel by mesoporous $\pi$-complexation adsorbents. Chem Eng Sci. 2009;64:5240-6. https://doi.org/10.1016/j.ces.2009.08.031.

Cychosz KA, Wong-Foy AG, Matzger AJ. Liquid phase adsorption by microporous coordination polymers: removal of organosulfur compounds. J Am Chem Soc. 2008;130:6938-9. https://doi.org/ 10.1021/ja802121u.

Duan L, Gao X, Meng X, et al. Adsorption, co-adsorption, and reactions of sulfur compounds, aromatics, olefins over $\mathrm{Ce}$ exchanged Y zeolite. J Phys Chem C. 2012;116:25748-56. https://doi.org/10.1021/jp303040m.

Ghassabzadeh H, Torab-Mostaedi M, Mohaddespour A, et al. Characterizations of $\mathrm{Co}$ (II) and $\mathrm{Pb}$ (II) removal process from aqueous solutions using expanded perlite. Desalination. 2010;261:73-9. https://doi.org/10.1016/j.desal.2010.05.028.

Hasan Z, Jeon J, Jhung SH. Oxidative desulfurization of benzothiophene and thiophene with $\mathrm{WO}_{x} / \mathrm{ZrO}_{2}$ catalysts: effect of calcination temperature of catalysts. J Hazard Mater. 2012;205-206:216-21. https://doi.org/10.1016/j.jhazmat.2011. 12.059 .

Hernández-Maldonado AJ, Yang FH, Qi G, Yang RT. Desulfurization of transportation fuels by $\pi$-complexation sorbents: $\mathrm{Cu}(\mathrm{I})$-, $\mathrm{Ni}(\mathrm{II})-$, and $\mathrm{Zn}$ (II)-zeolites. Appl Catal B Environ. 2005;56:111-26. https://doi.org/10.1016/j.apcatb.2004.06.023.

Jiang J, Ng FTT. Production of low sulfur diesel fuel via adsorption: an equilibrium and kinetic study on the adsorption of dibenzothiophene onto NaY zeolite. Adsorption. 2010;16:549-58. https://doi.org/10.1007/s10450-010-9259-5.

Khaled M. Adsorption performance of multiwall carbon nanotubes and graphene oxide for removal of thiophene and dibenzothiophene from model diesel fuel. Res Chem Intermed. 2015;41:9817-33. https://doi.org/10.1007/s11164-015-1986-5.

Li C, Jiang Z, Gao J, et al. Ultra-deep desulfurization of diesel: oxidation with a recoverable catalyst assembled in emulsion. Chem Eur J. 2004;10:2277-80. https://doi.org/10.1002/chem. 200305679.

Lin L, Zhang Y, Zhang H, Lu F. Adsorption and solvent desorption behavior of ion-exchanged modified $\mathrm{Y}$ zeolites for sulfur removal and for fuel cell applications. J Colloid Interface Sci. 2011;360:753-9. https://doi.org/10.1016/j.jcis.2011.04.075.

Nazal MK, Khaled M, Atieh MA, et al. The nature and kinetics of the adsorption of dibenzothiophene in model diesel fuel on carbonaceous materials loaded with aluminum oxide particles. Arab J Chem. 2015;2015:4. https://doi.org/10.1016/j.arabjc.2015.12. 003 (in press).

Ogunlaja AS, Coombes MJ, Torto N, Tshentu ZR. The adsorptive extraction of oxidized sulfur-containing compounds from fuels by using molecularly imprinted chitosan materials. React Funct Polym. 2014;81:61-76. https://doi.org/10.1016/j.reactfunctpo lym.2014.04.006.

Press WH, Teukolsky SA, Vetterling WT, Flannery BP. Numerical recipes in FORTRAN. The art of scientific computing. 2nd ed. Cambridge: Cambridge University Press; 1992.

Rashtchi M, Mohebali GH, Akbarnejad MM, et al. Analysis of biodesulfurization of model oil system by the bacterium, strain RIPI-22. Biochem Eng J. 2006;29:169-73. https://doi.org/10. 1016/j.bej.2005.08.034.

Ruthven DM. Principles of adsorption and adsorption processes. 1st ed. New York: Wiley; 1984.

Sano Y, Choi K, Korai Y, Mochida I. Adsorptive removal of sulfur and nitrogen species from a straight run gas oil over activated carbons for its deep hydrodesulfurization. Appl Catal B Environ. 2004;49:219-25. https://doi.org/10.1016/j.apcatb.2003.12.007.

Sari A, Tuzen M, Citak D, Soylak M. Adsorption characteristics of $\mathrm{Cu}$ (II) and $\mathrm{Pb}$ (II) onto expanded perlite from aqueous solution. J Hazard Mater. 2007;148(1-2):387-94. https://doi.org/10.1016/ j.jhazmat.2007.02.052.

Sentorun-Shalaby C, Saha SK, Ma X, Song C. Mesoporous-molecular sieve-supported nickel sorbents for adsorptive desulfurization of commercial ultra-low-sulfur diesel fuel. Appl Catal B. 2011;101:718-26. https://doi.org/10.1016/j.apcatb.2010.11.014.

Shen Y. Selective adsorption for removing sulfur: a potential ultradeep desulfurization approach of jet fuels. RSC Adv. 2012;2:1700-11. https://doi.org/10.1039/C1RA00944C.

Shi Y, Yang X, Tian F, Jia C, Chen Y. Effects of toluene on thiophene adsorption over NaY and Ce(IV) Y zeolites. J Nat Gas Chem. 2012;21:421-5. https://doi.org/10.1016/S1003-9953(11)60385$\mathrm{X}$.

Shi Y, Zhang W, Zhang H, et al. Effect of cyclohexene on thiophene adsorption over $\mathrm{NaY}$ and LaNaY zeolites. Fuel Process Technol. 2013;110:24-32. https://doi.org/10.1016/j.fuproc.2013.01.008.

Singh AP, Singh PC, Pandey KK, Singh VN. Adsorption of 1-butanethiol from kerosene oil on red mud. Can J Chem Eng. 1988;66:501-4. https://doi.org/10.1002/cjce.5450660324.

Song C. An overview of new approaches to deep desulfurization for ultra-clean gasoline diesel and jet fuel. Catal Today. 2003;86:211-63. https://doi.org/10.1016/S0920-5861(03)004127.

Song H, Jiang BL, Song HL, Jin ZS, Su XL. Preparation of AgY zeolite and study on its adsorption equilibrium and kinetics. Res Chem Intermed. 2015;41:3837-54. https://doi.org/10.1007/ s11164-013-1493-5. 
Song H, Cui XH, Song HL, Gao HJ, Li F. Characteristic and adsorption desulfurization performance of $\mathrm{Ag}-\mathrm{Ce}$ bimetal ionexchanged Y zeolite. Ind Eng Chem Res. 2014;53:14552-7. https://doi.org/10.1021/ie404362f.

Srivastav A, Srivastava VC. Adsorptive desulfurization by activated alumina. J Hazard Mater. 2009;170:1133-40. https://doi.org/10. 1016/j.jhazmat.2009.05.088.

Subhan F, Liu BS, Zhang QL, Wang WS. Production of ultra-lowsulfur gasoline: an equilibrium and kinetic analysis on adsorption of sulfur compounds over Ni/MMS sorbents. J Hazard Mater. 2012;239-240:370-80. https://doi.org/10.1016/j.jhazmat. 2012.09.012.

Sun HY, Sun LP, Li F, Zhang L. Adsorption of benzothiophene from fuels on modified NaY zeolites. Fuel Process Technol. 2015;134:284-9. https://doi.org/10.1016/j.fuproc.2015.02.010.

Tang M, Zhou $\mathrm{L}$, Du $\mathrm{M}$, et al. A novel reactive adsorption desulfurization $\mathrm{Ni} / \mathrm{MnO}$ adsorbent and its hydrodesulfurization ability compared with $\mathrm{Ni} / \mathrm{ZnO}$. Catal Commun. 2015;61:37-40. https://doi.org/10.1016/j.catcom.2014.11.005.

Tian WH, Sun LB, Song XL, et al. Adsorptive desulfurization by copper species within confined space. Langmuir. 2010;26:17398-404. https://doi.org/10.1021/la101856d.
Wang H, Song L, Jiang H, et al. Effects of olefin on adsorptive desulfurization of gasoline over Ce(IV) Y zeolites. Fuel Process Technol. 2009a;90:835-8. https://doi.org/10.1016/j.fuproc.2009. 03.004 .

Wang J, Xu F, Xie W, et al. The enhanced adsorption of dibenzothiophene onto cerium/nickel-exchanged zeolite Y. J Hazard Mater. 2009b;163:538-43. https://doi.org/10.1016/j. jhazmat.2008.07.027.

Wang Y, Yang RT. Desulfurization of liquid fuels by adsorption on carbon-based sorbents and ultrasound-assisted sorbent regeneration. Langmuir. 2007;23:3825-31. https://doi.org/10.1021/ la063364z.

Yin $Y$, Xue D, Liu $X$, et al. Unusual ceria dispersion formed in confined space: a stable and reusable adsorbent for aromatic sulfur capture. Chem Commun. 2012;48:9495-7. https://doi.org/ 10.1039/C2CC35388A.

Zhang X, Tang D, Zhang M, Yang R. Synthesis of NaX zeolite: influence of crystallization time, temperature and batch molar ratio $\mathrm{SiO}_{2} / \mathrm{Al}_{2} \mathrm{O}_{3}$ on the particulate properties of zeolite crystals. Powder Technol. 2013;235:322-8. https://doi.org/10.1016/j.pow tec.2012.10.046. 